\title{
A CONTRIBUIÇÃO DA ANTROPOLOGIA SIMÉTRICA À PESQUISA E INTERVENÇÃO EM PSICOLOGIA SOCIAL: UMA OFICINA DE EXPRESSÃO CORPORAL COM JOVENS DEFICIENTES VISUAIS ${ }^{1} 2$
}

\author{
Marcia Moraes \\ Universidade Federal Fluminense, Rio de Janeiro, Brasil
}

\begin{abstract}
RESUMO: Este trabalho visa discutir os modos de pesquisar com um grupo de deficientes visuais. $\mathrm{O}$ artigo relata o trabalho de uma Oficina de Expressão Corporal com jovens deficientes visuais. Nos referimos às pesquisas de Latour, Despret e Stengers para discutir os modos de produção de conhecimento com deficientes visuais. Partimos de uma problematização de um modo de intervir que considera o campo de pesquisa como algo fora de nós. A partir da antropologia simétrica de Latour, concluímos indicando que intervir é produzir realidades inéditas e que o papel do pesquisador é seguir os atores em ação.
\end{abstract}

PALAVRAS-CHAVE: Deficientes visuais; corpo; pesquisa; Antropologia Simétrica; Psicologia.

\section{THE CONTRIBUTION OF SYMMETRIC ANTHROPOLOGY TO INTERVENTION RESEARCH IN SOCIAL PSYCHOLOGY: A CORPORALEXPRESSION WORKSHOP WITH VISUAL HANDICAPPED YOUTHS}

\begin{abstract}
This paper aims to discuss how to carry out research with a group of visual handicapped youth. The text describes the work of a Corporal Expression Workshop with visual handicapped youth. To discuss the modes of producing knowledge with visual handicapped youth, we refer to Latour, Despret and Stengers. We start by problemizing the research field as something that is outside of our realm. Our final considerations, based on Latour's symmetric anthropology, indicate that to intervene is to produce unedited realities and that the work of the researcher is to follow the actors in action.
\end{abstract}

KEYWORDS: Visual handicapped; body; research; Symmetric Anthropology; Psychology.

Partindo do enfoque da antropologia simétrica proposta por Bruno Latour este artigo tem o objetivo de discutir e analisar alguns modos de pesquisar em Psicologia Social. Destacamos desde logo que nossa leitura das teses da antropologia simétrica tem sido realizada em articulação com os trabalhos de V. Despret, psicológa belga, ligada ao campo da antropologia simétrica que tem publicado diversos livros acerca da história e da epistemologia da psicologia (Despret, 1999, 2004a, 2004b). Neste artigo fazemos uma apresentação da pesquisa de campo que realizamos com um grupo de jovens deficientes visuais, no Instituto Benjamin Constant (IBC), um centro de referência em deficiência visual, situado no bairro da Urca, no Rio de Janeiro. Os impasses que encontramos no trabalho de campo nos fizeram problematizar os modos de pesquisar em psicologia social.

\section{Díficeis Começos: Cego Sonha?}

No ano de 2004 formamos um grupo de pesquisa que contava com a participação de pesquisadores ligados à psicologia ${ }^{3}$, a professora de teatro do $\mathrm{IBC}^{4} e$ os alunos desta instituição regularmente inscritos nas oficinas de teatro.

Iniciamos a pesquisa observando as atividades da Oficina de Teatro que tinham por objetivo montar uma peça ao final do ano letivo e que seria encenada no Teatro do IBC. Neste momento, nossa observação não se guiava por nenhuma questão prévia e claramente delimitada. $\mathrm{O}$ que nos movia era a curiosidade de conhecer o que é o conhecer sem o ver. Fomos nos inserindo naquele coletivo e com ele fomos sendo afetados, modificados em nossas formas de pensar e de agir. Acompanhávamos as muitas derivas daquele grupo, os seus problemas, a diversidade de relações entre os jovens alunos, namoricos, rivalidades, amizades, personagens, cenários, as formas de funcionamento da instituição, por vezes paradoxais. Que actantes seguir ${ }^{5}$ ? Que feixe de relações nos interessariam?

$\mathrm{O}$ grupo de teatro era formado por jovens com diferentes condições visuais. Havia pessoas com resíduos visuais diversos, outros considerados cegos. Essa constatação se chocava com os nossos modos anteriores de falar da cegueira. Para nós, cegos eram aqueles que não enxergavam e o IBC era uma instituição voltada 
para os cegos. Mas no cotidiano daquele grupo, fomos notando que as fronteiras que separam os cegos dos videntes não eram tão nítidas. São consideradas cegas muitas pessoas que possuem alguns resíduos visuais, que são, portanto, capazes de perceber as diferenças de luminosidade, de discriminar visualmente algumas mudanças no ambiente, de perceber vultos. Consultando a literatura sobre este assunto optamos por seguir uma definição funcional de cegueira ${ }^{6}$ : são considerados cegos aqueles que fazem uso do Sistema Braille como forma exclusiva de aprendizagem da leitura e da escrita. Esta definição nos equipou durante algum tempo, mas a todo momento, durante as Oficinas de Teatro, o tema dos limites, das fronteiras entre o ver e o não ver era retomado. Esse tema aparecia de diversas maneiras. De um lado, aparecia na composição dos personagens: como levar uma menina que nasceu cega e que não tinha nenhum referencial visual de uma bailarina a interpretar um personagem que era bailarina? Por que ensinar a um cego a dar tchau com a mão se este é um gesto típico dos videntes? Como transmitir a uma menina cega o sentido de um outro gesto tipicamente visual: o "bater de ombros" quando se quer demonstrar para o outro um certo descaso, um desprezo? Eram questões que mobilizavam aquele grupo e que nos afetavam de modo particular porque instigava e alimentava nossa curiosidade sobre os modos de conhecer do cego e, ao mesmo tempo, nos incluía no problema: como nos relacionamos com este grupo? Sem que nós soubéssemos, íamos pouco a pouco fazendo parte dos problemas que atravessavam a pesquisa.

De outro lado, na montagem da peça era preciso levar em conta o fato de que ela seria encenada no Teatro do IBC, com uma platéia formada por pais, professores e alunos da instituição: uma platéia, portanto, completamente heterogênea quanto às suas condições visuais. Nela havia pessoas cegas, com baixa visão e videntes. Logo, era fundamental que a peça encenada pudesse criar um campo de sentido, de entretenimento que articulasse esse grupo heterogêneo.

Movidos por estes problemas, optamos por buscar as respostas fazendo entrevistas semi-estruturadas com os jovens que participavam da Oficina de Teatro. Queríamos saber como o cego conhece, como ele se relaciona com os videntes, como ele conhece o mundo Elaboramos nosso roteiro de questões e "fomos a campo".

Uma de nossas primeiras entrevistas foi com um jovem de 16 anos que havia ficado cego aos dois anos de idade. Perguntamos a ele, entre outras coisas: "você sonha?" Ainda que de modo subreptício, tínhamos já uma resposta para esta pergunta: ele não deve sonhar, já que o sonho é eminentemente uma experiência visual. Para nosso espanto o jovem disse que sonhava, sonhava que estava metrô, sempre sonhava com o metrô. E nós, decididas a "encontrar" uma resposta para nossa pergunta insistía- mos: "mas sonha como? O que aparece no seu sonho?" E o jovem resistia: "sonho com o metrô! O metrô vem e vai toda hora, para entrar na estação do metrô tem que passar por uma escada. Sonho com isso.” Fomos implacáveis, insistimos de todas as formas, até não mais poder e finalmente perguntamos: "no seu sonho tem imagens?"

Transcrevemos as entrevistas e as lemos no encontro do grupo de pesquisa. A leitura em grupo fez ressoar uma estranheza em nosso "modo de coletar os dados", um equívoco no uso que fizemos da entrevista semiestruturada, um mal-entendido promissor.

\section{Da Extorsão de Testemunhos aos Mal Entendidos Promissores}

Isabelle Stengers (1990), Bruno Latour (2000) e Vinciane Despret (1999, 2004a, 2004b) são autores que tomamos como aliados e que nos forçam a pensar e a problematizar nosso trabalho de pesquisa. Stengers (1990) apresenta uma importante discussão sobre os sentidos do fazer ciência. Em linhas gerais, a tese da autora, com a qual concordam Latour e Despret, é a de que a ciência é uma prática que "faz falar" um fenômeno. O que significa fazer falar? Pois não era justamente o que queríamos quando entrevistamos o jovem para saber como ele sonha?

Tratando das ciências sob o signo do acontecimento Stengers (2002) analisa os dispositivos de conhecer inventados pela ciência moderna, particularmente com a figura de Galileu. Diferentemente do enfoque epistemológico defendido por Koyré, Stengers (2002) propõe investigar não as operações racionais que justificam o conhecimento científico, mas os dispositivos que fazem existir um fenômeno: o acento é na ciência como uma prática, uma ação engajada que mobiliza atores díspares e heterogêneos, inventando e produzindo novos seres com os quais temos que negociar e que pactuar formas de vida em comum. Tal é a tese da antropologia simétrica de Bruno Latour (2000) acerca do conhecimento científico: a ciência não é resultado do funcionamento da razão, atributo de um sujeito dado e separado do contexto social e político. A ciência é uma prática híbrida que não cessa de articular, conectar atores heterogêneos, humanos e não humanos. Desse modo, as tradicionais categorias que embasaram o pensamento moderno são colocadas em xeque: natureza e sociedade, sujeito e objeto, pesquisador e pesquisado não são domínios separados e estanques. São efeitos de nossas práticas híbridas, suas fronteiras são pactuadas e renegociadas pelos coletivos. É nesse sentido, que Latour (2000) fala não mais em sociedade, mas em coletivos socio-técnicos. Isso porque o termo sociedade, impregnado por um modo de pensar que separa humanos e não humanos, parece indicar apenas um modo de relação entre homens. 
A noção de coletivo aponta para o caráter híbrido, mestiço, rizomático que marca nossas práticas. Trata-se, portanto, de orientar-se filosoficamente por uma concepção "construtivista" - termo que Latour (2002) retoma e define como uma construção da realidade que não é nem puramente social, nem puramente individual. Trata-se de uma construção que aposta nas conexões, nas alianças entre atores humanos e não humanos. Por essa via, o autor afirma que o real é tanto mais verdadeiro quanto mais for construído (Latour, 2002), isto é, quanto mais um fato mobilizar aliados, quanto mais articulações ele possuir, tanto mais real ele será. Um "fato" isolado, desconectado de outros atores é uma ficção (Latour, 2000). A verdade é, portanto, um ponto de chegada e não um ponto de partida. Ponto de chegada construído, negociado, pactuado e por isso mesmo, sempre parcial, histórico, provisório. Nesse sentido, importa tomar a ciência em ação, a ciência tal como ela se faz nas bancadas dos laboratórios, nos campos de pesquisa. Se tomamos a ciência feita, pronta e acabada - como fez, por exemplo, Koyré - consideramos apenas um lado da ciência, aquele dos vencedores, dos fatos que se consolidaram, que ampliaram suas redes e se tornaram verdadeiros. A proposta de Latour (2000)- e nisso Stengers (1990) e Despret (1999) concordam com o autor - é de tomar a ciência em ação, assumindo um olhar antropológico sobre as práticas científicas. Do ponto de vista histórico, importa seguir as controvérsias, os impasses, os pontos de bifurcação e indecisão, ou seja, aqueles pontos na história das ciências nos quais os fatos ainda não se consolidaram, nos quais as fronteiras entre o fato e a ficção estão ainda sob negociação.

Discutindo a produção de conhecimento na ciência, Stengers (1990) escolhe a palavra testemunha no lugar de objeto do conhecimento. Diz a autora:

empregarei o termo 'testemunha', pois contrariamente ao termo objeto, não há diferença entre as ciências que tratam de seres falantes, ou as que tratam de seres que não falam. A ciência faz falar sujeitos. $\mathrm{O}$ essencial aqui será o 'fazer falar': os objetos e sujeitos devem dar testemunho da legitimidade da maneira pela qual os fazem falar. As controvérsias científicas têm como problema a legitimidade desses testemunhos (controvérsias experimentais) e o seu alcance (controvérsias teóricas ou conceituais). (Stengers, 1990, p. 84).

De que modo fazemos falar? Quais são os dispositivos que utilizamos para fazer falar? Nas ciências experimentais - e Galileu neste sentido é um caso exemplar o fazer falar é sempre uma questão de controle e de purificação. "Um bom fato experimental só aceita falar uma língua" (Stengers, 1990, p. 85). Controlar e purificar implica retirar do fato tudo o que obscurece o sentido do testemunho, tudo o que produz opacidade. Da precisão destas estratégias de controle e purificação resulta a distinção entre um fato e um artefato, isto é, um testemunho extorquido.

Se podemos dizer que ele [o cientista] confundiu um fato com um artefato, podemos dizer que ele extorquiu um testemunho. Ao invés de fazer falar, no sentido de purificar, de controlar de tal maneira que o testemunho se livre de seus parasitas, ele impôs uma relação de força unilateral. (Stengers, 1990, p. 85-86).

Em nosso trabalho de pesquisa não nos movíamos no referencial da pesquisa experimental. Ao contrário, situávamos nosso trabalho na esteira das pesquisas participantes, herdeira das importantes contribuições de Kurt Lewin para a psicologia ${ }^{7}$. No entanto, flagramos em nossa prática, em nosso cotidiano de pesquisa, marcas e tradições de um fazer ciência do qual pretendíamos nos afastar. Dizíamos que estávamos fazendo pesquisa de campo - entendendo que o campo estava lá, no IBC, enquanto nós pesquisadores estávamos na academia, nos congressos, falando em nome dos sujeitos investigados. Coletávamos dados, como se os dados estivessem no campo esperando para ser recolhidos e organizados num quadro de referência feito, pensado e elaborado por nós, pesquisadores. Assim, embora estivéssemos encharcados de leituras que passavam ao largo da modernidade, nossa prática era moderna ${ }^{8}$. Ao entrevistar o jovem cego tínhamos uma hipótese: os cegos não têm imagens visuais, logo eles não devem sonhar. Era preciso que o jovem confirmasse essa hipótese, daí a nossa insistência, as perguntas cada vez mais incisivas.

Nesse cenário de pesquisa, a recalcitrância ${ }^{9}$ se fez presente, isto é, o jovem resistia e não nos oferecia a resposta esperada, ao contrário, ele dizia "eu sonho como todo mundo sonha, ué!". Ao mesmo tempo, esta recalcitrância produzia deslocamentos em nosso modo de pesquisar. $\mathrm{O}$ que fazer com a recalcitrância? Tomar como variável estranha? Classificar como margem de erro da pesquisa? Estávamos nos dando conta de que extorquíamos um testemunho, queríamos transformá-lo num fato. Esse mal entendido foi um ponto decisivo, um ponto de bifurcação em nosso trabalho de pesquisa. Foi para nós um mal entendido promissor, isto é, um mal entendido:

que produz novas versões disto que o outro pode fazer existir ... O mal entendido promissor, em outros termos, é uma proposição que, da maneira pela qual ela se propõe, cria a ocasião para uma nova versão possível do acontecimento ... (Despret, 1999, p. 328-330).

Desse modo, o sujeito interrogado não é mais um simples objeto de investigação, ele é quem fornece ao pesquisador as suas questões. Perguntar se o cego sonha, como ele sonha, se ele tem ou não imagens visuais 
era uma questão para nós, mas não para o jovem. O mal entendido é promissor quando coloca em risco a nossa observação, os nossos modos de interrogar o outro. Estávamos, portanto, na iminência de transformar tanto os nossos modos de conhecer, quanto as versões sobre o que é a cegueira, o que é intervir num grupo de jovens deficientes visuais.

Despret (2004b) nos fazia lembrar o que define a singularidade (e os riscos) da experiência de interrogar os vivos: a interrogação é uma situação social onde jamais é anódino o engajamento daqueles que dela participam.

Dito de outro modo, aqueles que observamos também nos observam e isso não é de modo algum sem importância. A observação implica riscos, implica, conforme Despret (2004b) um processo de afetação recíproco que algumas versões da história da psicologia experimental quiseram esquecer. Atualizamos esta versão de psicologia quando extorquimos o testemunho do jovem cego.

No entanto, a partir daquele mal entendido retificamos nossos modos de agir e de intervir naquele grupo. A recalcitrância do jovem fez com que nos déssemos conta de que talvez não estivéssemos fazendo as boas perguntas, isto é, aquelas perguntas nas quais aquele jovem -e o grupo - podia se articular. Nas palavras de Despret (2004b) "uma das formas de resistir a um aparato é levar o experimentador a transformar suas questões em novas questões de tal modo que elas sejam as questões apropriadas de se fazer para aquele individuo em particular" (p. 124). Desse modo, o dispositivo de conhecimento é um processo simétrico de transformação recíproca, do pesquisador e do pesquisado. O conhecer é, neste sentido, um processo de afetação recíproca. Conhecer é interessar - estar entre, fazer link (Despret, 2004b) Era uma outra versão de pesquisa que se tornava presente em nosso trabalho. Uma outra versão do que é produzir conhecimento.

\section{Modos de Intervir e Pesquisar num Grupo de Deficientes Visuais}

Depois de um ano de observação das atividades da Oficina de Teatro, fomos convidadas a organizar uma Oficina de Expressão Corporal cujo objetivo era promover experimentações corporais que levassem os alunos a elaborarem os seus personagens. Foi no contexto destas Oficinas que circunscrevemos os problemas que passaram a nos orientar no trabalho de campo: de um lado, investigar o lugar das experimentações corporais na elaboração dos personagens a serem interpretados pelos jovens com deficiência visual na peça de teatro que estavam montando e, de outro lado, investigar os modos pelos quais os limites entre o ver e o não ver eram pactuados e construídos pelo grupo. As Oficinas eram planejadas e organizadas a partir das dificuldades que cada um dos jovens encontrava para construir o seu personagem.
Logo, as questões em torno das quais planejávamos nossas ações eram levantadas pelos jovens. As Oficinas ocorriam uma vez por semana, com duração de uma hora e meia cada encontro. Participavam deste trabalho 11 alunos que estavam ensaiando a peça, com idades que variavam de 11 a 17 anos e com condições visuais diferentes, isto é, havia três jovens cegos e oito com baixa visão. A construção e elaboração das posturas corporais dos personagens era um processo laborioso que tocava nos limites entre o ver e o não ver, isto é, a heterogeneidade das condições visuais do grupo produzia uma série de impasses. Considerando que na platéia havia pessoas cegas e com baixa visão, os impasses eram também da diretora da peça, era preciso criar recursos que traduzissem em linguagem oral e sonora tudo o que se passava no espetáculo, desse modo os cegos da platéia e os atores cegos podiam acompanhar o que se passava em cena.

Durante o período que observamos as Oficinas de Teatro pudemos notar que para um criança cega era muito difícil inventar corporalmente um personagem apenas com as explicações verbais da professora. De nada adiantava dizer para esta pessoa: "agora o personagem dá de ombros"! Como dissemos acima, dar de ombros é um gesto típico dos videntes, mas que não fazia sentido nenhum para os cegos. Ou ainda, quando uma menina cega de nascimento vai interpretar uma bailarina, de nada adiantava dizer-lhe: "a bailarina gira, anda na ponta dos pés!" Os movimentos que ela produzia a partir destas palavras eram mecânicos, sem vida, sem emoção. Era preciso produzir mais e mais articulações, mobilizar os corpos daquelas pessoas para criar um campo de ação e de conhecimento que fizesse sentido para elas e para nós. $\mathrm{O}$ eixo do trabalho era, portanto, intervir num espaço entre o ver e não ver. As intervenções passaram a ser pactuadas com o grupo, negociadas - estar entre $o$ ver e o não ver inaugurava a possibilidade de criarmos um mundo comum (Latour, 2003). A expressão mundo comum não é tomada aqui como sinônimo de um mundo único. Ao contrário, Latour (1999) ao falar da construção de um mundo comum chama a atenção para o processo de negociação, de mobilização de actantes diversos e heterogêneos que compõem nossos coletivos. A cada novo actante que é mobilizado, o coletivo se reconfigura, se refaz, assume outras formas. Assim, o mundo comum é um multiverso, isto é, é feito pela articulação de diferenças e não pela composição de unidades estáveis que transcendam as suas condições de produção.

No trabalho da Oficina de Expressão Corporal considerávamos que para produzir as "experimentações corporais" era preciso promover cada vez mais articulações entre o corpo e o mundo. Corpo para nós não era tomado como uma essência, uma substância que se opõe a uma alma imaterial, mas antes como uma: 
interface que se torna mais descritível quando aprende a ser afetada por mais e mais elementos. O corpo não é a residência provisória de algo superior - uma alma imortal, o universal ou o pensamento - mas aquilo que deixa uma trajetória dinâmica pela qual nós aprendemos a registrar e a nos tornar sensíveis para aquilo de que o mundo é feito. Tal é a grande virtude desta definição: não há sentido em definir o corpo diretamente, mas apenas tornando o corpo sensível ao que estes outros elementos são. (Latour, 1999, p. 1)

Nossas ações com o grupo eram organizadas pelas questões que ali apareciam, buscávamos intervir com o grupo negociando ali as ações que seriam levadas a cabo. Um dos meninos que participava daquele grupo iria interpretar na peça um palhaço de mola, daqueles que saltam de uma caixa quando dela se retira a tampa. $\mathrm{O}$ menino iniciava a peça dentro da caixa, escondido, até que outro personagem abria a caixa e ele devia pular e balançar o corpo como se fosse uma mola. Neste momento da pesquisa este menino, que estava com 12 anos, havia acabado de perder definitivamente a visão. E ele nos disse: "quando eu enxergava eu nunca vi uma mola, como é que uma mola balança?". Levamos para o grupo molas de diferentes tensões e também vários tipos de palhaços que pulam de caixas. $\mathrm{O}$ menino tocava as molas, puxava-as e com as mãos observava os efeitos que seu toque produzia na mola e dizia: "cego é muito curioso". Ele também observava os palhaços, mas nestes as molas estavam ocultas, cobertas pelas roupas do boneco. Guiando-se pelo tato o menino dizia: "com este eu 'vejo' melhor a mola, porque 'vejo' como o palhaço balança, como ele mexe depois de sair da caixa". E virando-se para uma de nós da pesquisa concluía: "Com este palhaço você é que fica cega não é? Porque você não 'vê' a mola e não sabe "ver' com a mão".

O menino tirou uma conclusão importante desse processo: "as molas grandes balançam mais, as pequenas quase não balançam. Acho que o meu palhaço vai ter uma mola grande". Quanto mais ele se articulava com as molas, mais ele se tornava sensível a um mundo-mola, mais o seu corpo ia se afetando pela elasticidade da mola. É importante lembrar que estas atividades eram realizada em grupo, todos participavam das experimentações tateando os objetos, falando sobre o que é um palhaço, como ele se veste, o que ele faz num circo. Alguns membros do grupo já tinham ido ao circo e tinham memórias visuais do palhaço. Assim, as experimentações articulavam as histórias que cada um contava sobre palhaços, as lembranças de cada um, as molas, as roupas do palhaço, músicas de palhaço, as gargalhadas, o fazer rir do palhaço. Para o menino a referência de palhaço vinha de "coisa que ele tinha visto na televisão, como o programa do Chaves." 10
Um passo importante dessa experimentação foi dado depois de dois encontros: o menino começou a deixar o seu corpo se afetar pela mola, começou a balançar as pernas como se elas fossem molas. De início, apenas as pernas balançavam. E o grupo sugeriu: "mas se a mola é grande, o palhaço tem que balançar mais do que as pernas". Pouco a pouco o movimento da mola foi invadindo o corpo do menino, o corpo do grupo: ali começava a surgir o palhaço daquele menino. Palhaço singular, único, ao qual o menino acrescentou algumas outras características: ele era distraído, roncava alto quando dormia e tinha um bom coração. Outros elementos foram sendo introduzidos naquele contexto: as roupas, o cabelo, a caixa, o nariz de palhaço. Formamos um grupo-palhaço com o qual o menino se articulava e a partir do qual ele construiu o seu personagem. Consideramos com Despret (2004b) que o conhecimento do palhaço de molas pelo menino se deu num processo de transformação, de afetação e de envolvimento com os actantes que se fizeram presentes naquele contexto.

A construção do personagem operava longe dos verbalismos tão presentes na educação do deficiente visual. Na educação, o verbalismo se faz presente quando as ações educativas são construídas e elaboradas distantes dos referenciais que o deficiente visual possui para conhecer o mundo. Assim, o professor é aquele que transmite um conhecimento que o aluno repete passivamente. Nesse caso, o aluno deficiente visual repete o que lhe é transmitido, sem, no entanto, encarnar, incorporar em sua experiência isso que ele repete (Masini, 1994).

$\mathrm{Na}$ construção dos personagens vimos que o verbalismo era insuficiente para a transformação daqueles que estavam ligados às atividades da Oficina de Teatro. Intervir entre o ver $e$ o não ver é colocar-se o desafio de intervir com o grupo e não sobre o grupo. Nesse caso, somos partes do campo de pesquisa, o campo não está fora de nós, aguardando por nossas soluções, nossos quadros de referência. Estamos no campo quando falamos dele, quando contamos histórias como esta que aparece neste texto. Nossas perguntas vão sendo tecidas com o grupo, são formadas de materialidades e socialidades que se conectam, se agenciam e fazem falar os sujeitos que ali estão, inclusive nós pesquisadores (Spink, 2003).

Nesse processo, os mal entendidos são positivos porque eles são vetores de transformação e não variáveis a serem controladas, purificadas. Produzir conhecimento com o grupo nos coloca diante de desafios éticos, políticos e estéticos.

Éticos porque tomamos o grupo como um híbrido de socialidade e materialidade, uma plano de conexões múltiplas e heterogêneas que faz de nós pesquisadores, diplomatas, negociadores envolvidos em mobilizar alia- 
dos que podem ou não ser articulados com aquele coletivo. Nossa entrevista semi-estruturada articulou-se mal com aquele grupo, o jovem recusou-se a se articular com aquele dispositivo, exigindo de nós que nos transformássemos se quiséssemos continuar como membros daquele grupo. Intervir entre o ver e o não ver implicava um posicionamento distinto do enfoque comparativo que caracteriza uma boa parte dos trabalhos com deficientes visuais (Batista, 2005; Santin \& Simmons, 1977/1996). No enfoque comparativo "as capacidades e características de crianças cegas são avaliadas em relação às capacidades correspondentes de crianças videntes, sempre em relação à idade cronológica" (Batista, 2005, p. 11). Por esta via, a criança cega é caracterizada como deficiente, é marcada pela concepção de que lhe falta a visão. É a concepção de déficit que se faz presente neste enfoque. Na perspectiva que defendemos neste trabalho, o espaço entre o ver $e$ o não ver é aquele que toma a diferença como positividade. Tal enfoque nos coloca diante de uma questão ética que consiste em operar num plano de multiplicidades: nele podemos seguir linhas diversas, linhas normatizantes, docilizantes ou linhas inventivas e criadoras. Trata-se de "abrir o corpo a conexões que supõem todo um agenciamento, circuitos, conjunções, superposições e limiares, passagens e distribuições de intensidade, territórios e desterritorializações medidas à maneira de um agrimensor" (Deleuze \& Guattari, 1996, p. 22). Portanto, nossa questão ética diz respeito ao agir no plano das multiplicidades sem recorrer a modelos ou formas unitárias que lhe sobrecodifiquem.

Não duvidamos de que nossas ações com este grupo são de caráter micro-político porque ali problematizamos as relações entre o ver e não ver, negociamos, como dissemos acima, um multiverso e não um universo. Tangenciamos questões que dizem respeito aos sentidos da inclusão. O que é incluir alguém numa sociedade? Nosso trabalho nos permite colocar em xeque esta pergunta já que ela se constitui nos moldes do pensamento purificador: o indivíduo está de um lado, a sociedade de outro. Construir um multiverso exige uma transformação recíproca que implica o pesquisador e o pesquisado.

Buscamos uma intervenção que se faça de modo imanente, isto é, uma intervenção cujas ações sejam pactuadas com o grupo e que implique uma transformação do próprio ato de pesquisar. $\mathrm{O}$ fazer falar no sentido que tomamos como base nesse trabalho é um processo de produção, de invenção de algo que não estava dado de antemão. O palhaço que o menino criou era único, singular, não generalizável. O dispositivo que levou à construção do palhaço foi uma oportunidade de existência para um fenômeno inteiramente original e inédito (Despret, 2004a). Neste sentido, consideramos que este trabalho tem uma dimensão estética na exata medida em que ele engaja uma prática produtora de novos seres (Stengers, 2002).

\section{Considerações Finais}

Consideramos que a antropologia simétrica tem nos levado a redefinir o campo da pesquisa em psicologia. Isso porque, conforme expusemos acima, tomamos a psicologia como prática híbrida e mestiça, que articula actantes díspares e heterogêneos. A atividade de pesquisar nos coloca como partes do campo, mais um actante que produz efeitos, que se modifica na medida em se engaja com a pesquisa. Conhecer é um processo ativo, que implica afetar-se, transformar-se. Não chegamos a verdades generalizáveis, que valham para além de suas condições de produção. Descrevemos nossos modos de agir esperando mobilizar outros aliados que se disponham a estar conosco nesse desafio de tomar a pesquisa como atividade engajada, arriscada, da qual nunca conseguimos antecipar, prever e controlar todos os efeitos. Partilhamos com os outros os nossos mal entendidos promissores, aqueles que nos fizeram diferir. Insistimos na pertinência e na positividade do mal entendido uma vez que ele nos dá pistas de que para formular as boas perguntas precisamos mudar de rumo. Com este trabalho nos expusemos às reflexões sobre as questões éticas, políticas e estéticas que esta pesquisa nos traz. O que é intervir num coletivo híbrido? O que é intervir entre o ver e o não ver? Intervir sem ter de antemão o plano completo do vôo. Negociar, pactuar, mobilizar atores heterogêneos para construir um multiverso de deficientes visuais, videntes, molas, palhaços.

Em nosso trabalho de pesquisa concordamos com Despret quando ela afirma que:

Desapaixonar o conhecimento não nos dá um mundo mais objetivo, nos dá apenas um mundo sem nós, e logo, sem eles - linhas são traçadas muito rapidamente. E enquanto o mundo aparece como um mundo com o qual nós não nos importamos, ele se torna um mundo empobrecido, um mundo de mentes sem corpos, de corpos sem mentes, corpos sem corações, expectativas, interesses, um mundo de autômatos entusiastas observando criaturas estranhas e mudas; em outras palavras, um mundo pobremente articulado. (Despret, 2004b, p. 131).

Sintetizando em poucas palavras as contribuições da antropologia simétrica para os modos de pesquisar em psicologia, dizemos que:

1. O campo é um coletivo que articula humanos e não humanos, coletivo híbrido, mestiço, múltiplo no qual o que está em questão são as conexões e os efeitos que elas produzem. Desse modo, a antropologia simétrica nos permite redefinir o social: se num enfoque tradicional, que Latour chama de sociologia do social, a palavra social remete a uma relação entre homens, apenas homens, na perspectiva da antropologia simétrica o social diz respeito a um coletivo no qual estão conectados humanos e não humanos. 
2. Neste coletivo duas questões são relevantes: (a) a perfomance e (b) a intervenção. A perfomance nos indica que a conexão entre humanos e não humanos produz efeitos, faz existir fenômenos inéditos, logo a tarefa do pesquisador é seguir estes efeitos. A intervenção num coletivo implica um processo de negociação com as questões que atravessam o coletivo, ou seja, a negociação precisa levar em conta quais são as boas questões a serem formuladas para aquele grupo.

3. Os mal entendidos são promissores porque são vetores de transformação do conhecer, se tomados positivamente, os mal entendidos fazem derivar as intervenções do pesquisador.

4. A pesquisa é um processo de transformação recíproca - tanto do pesquisado, quanto do pesquisador. Pesquisar é engajar-se num coletivo, é interessar-se pelo que interessa ao outro, deixar-se afetar pelo que afeta ao outro.

5. No nosso trabalho de campo o corpo foi considerado como um efeito de conexões - as conexões performam um corpo que não estava dado antes, logo, no caso de nossa pesquisa, o corpo-mola foi produzido, foi feito pela conexão singular, única que o menino estabeleceu com as molas, com os diversos palhaços de mola que tateou, com os narizes de palhaço, com o texto do seu personagem, com os colegas de grupo, com as pesquisadoras. Estas alianças performaram um palhaço que é um híbrido, um coletivo que articula actantes díspares.

6. Os conhecimentos assim produzidos não são generalizáveis no sentido de uma ampliação de sua aplicabilidade a diferentes coletivos. Se conhecer é interessar, é mobilizar actantes, é fazer conexões, então podemos dizer que os conhecimentos que produzimos serão "generalizados" se redefinirmos este termo para considerá-lo em outro sentido. Assim, dizemos que "generalizamos nossos resultados" na medida que outros actantes se articulem com este trabalho, seja na leitura deste artigo, seja na formação de novos pesquisadores interessados em seguir os actantes em ação, seja nos congressos científicos nos quais este trabalho for apresentado. O trabalho será tanto mais "generalizado" quanto mais conexões estabelecermos, mas como vimos, as conexões são performativas, elas produzem novos efeitos, assim, podemos dizer que os resultados de nossa pesquisa são "generalizáveis" na exata medida em que são renegociados, refeitos, deslocados por novos actantes que a ele se conectam.

7. Pensar a pesquisa em psicologia neste referencial implica considerar que o trabalho de campo se faz com o outro e não sobre outro, implica ainda falar de uma intervenção que é fabricadora de realidades que não estão dadas, mas são efeitos de negociações e articulações entre humanos e não humanos.
8. As intervenções que realizamos operavam longe das dicotomias modernas que separam sujeito e objeto de pesquisa, cegos e videntes: operamos num espaço entre o ver e o não ver, buscamos seguir os modos como as fronteiras entre o ver e não ver são negociadas naquele grupo.

9. Trata-se de afirmar uma psicologia longe dos referenciais modernos de definir o conhecer.

O que narramos neste texto foi apenas um episódio de uma pesquisa que continua em ação. Chegando ao final deste artigo, temos a impressão de que pesquisar é narrar histórias ao modo de Sherazade, personagem das Mil e uma noites, que todas as noites contava uma história ao rei Shariar, entretendo-o, instigando-lhe a curiosidade, sem chegar a um desfecho definitivo nas histórias que contava.

No nosso último encontro na Oficina de Expressão Corporal uma das pessoas do grupo, que tem baixa visão, quis vendar os olhos durante a Oficina "para experimentar como é ficar sem enxergar." O menino - aquele que interpretou o palhaço de molas - manifestou-se enfaticamente contra o uso das vendas. Argumentava que ser cego não é o mesmo que ficar vendado, ser cego disse ele:

é um outro mundo, o vidente tem um mundo, o cego tem outro mundo. Um vidente coloca uma venda, depois tira e volta a enxergar. Quem vai tirar a venda que eu tenho nos olhos? Ninguém, ela é para sempre, minha cegueira é real.

E dirigindo-se para nós ele disse: “aqui no grupo vocês se interessam pelo cego, vocês querem saber como nós vemos o mundo, mas e lá fora, alguém se interessa por nós?" Ouvimos as palavras do menino, seguimos as pistas que a polêmica das vendas trouxe para o grupo e agora nos perguntamos acerca da pertinência de nos aproximarmos dos cegos usando um dispositivo que "simula" a cegueira.

\section{Notas}

1. O trabalho contou com o apoio financeiro do Programa Institucional de Bolsas de Iniciação Científica (PIBIC) da Fundação Carlos Chagas Filho de Amparo à Pesquisa do Estado do Rio de Janeiro (FAPERJ) e do Conselho Nacional de Desenvolvimento Científico e Tecnológico $(\mathrm{CNPq})$. Agradeço à professora de teatro do Instituto Benjamin Constant (IBC) Marlíria Flávia Coelho da Cunha. Agradeço também aos profissionais do IBC que me acolheram naquela instituição, aos responsáveis pelas crianças que autorizaram a realização da pesquisa. Por fim, agradeço de modo especial às alunas de graduação em Psicologia da Universidade Federal Fluminense que estiveram vinculadas a esta pesquisa através do programa de iniciação científica: Luciana de Oliveira Pires Franco, Ana Gabriela Rebelo dos Santos, Aline Alves de Lima, Carolina Cardoso Man- 
so, Isabela Prince.

2. Este artigo foi escrito como parte da proposta de número temático para Revista Psicologia e Sociedade organizada pelo GT da Associação Nacional de Pesquisa e Pós-Graduação em Psicologia (ANPEPP) Cotidiano e Práticas Sociais.

3. A equipe de pesquisa era coordenada pela autora. Dela participavam as seguintes alunas da graduação em Psicologia da Universidade Federal Fluminense: Luciana de Oliveira Pires Franco, Ana Gabriela Rebelo dos Santos, Aline Alves de Lima, Carolina Cardoso Manso, Isabela Prince.

4. Professora Marlíria Flávia Coelho da Cunha..

5. O termo actante é utilizado por Bruno Latour (2000) para designar tudo aquilo que tem agência, que produz efeitos no mundo. Para evitar confusões com a noção de ator utilizada no campo da sociologia, Latour utiliza o termo actantes. Enquanto no referencial sociológico o termo ator se refere aos humanos, no enfoque proposto por Bruno Latour (2000) actantes são coisas, pessoas, instituições, humanos e não humanos.

6. Para a definição de cegueira adotamos critério funcional ou educacional indicado por Amarilian (1997). Segundo este referencial é considerado cego o sujeito que faz uso exclusivamente do Sistema Braille para a leitura e a escrita e é considerado portador de baixa visão aquele que, através de recursos óticos, lê e escreve fazendo uso de material impresso em tinta. Assim, sabemos que alguns dos sujeitos cegos possuíam algum resíduo visual - por exemplo, a capacidade de distinguir luz e sombra, capacidade para perceber alguns obstáculos. Os sujeitos que ficaram cegos antes dos cinco de idade são considerados cegos congênitos.

7. Para conhecer as contribuições de Lewin para a psicologia ver Spink (2003); Rocha e Aguiar (2003).

8. Para a definição de modernidade seguimos Latour (1994). Para este autor a modernidade se define por um conjunto de práticas de purificação que produz zonas ontológicas distintas: sujeito e objeto, natureza e sociedade. No entanto, quanto mais purificadoras são estas práticas, mais elas produzem seres inclassificáveis, isto é, seres que não se enquadram nem em nenhum dos dois pólos que caracterizam a modernidade. Tais seres híbridos articulam de modo indissociável aquilo que as práticas purificadoras pretendem segregar. $\mathrm{O}$ autor sublinha que jamais fomos modernos, jamais nos encaixamos nos pólos que marcam a modernidade e o desafio atual da antropologia simétrica é o de pensar as ciências e as técnicas longe destes pólos.

9. A noção de recalcitrância é proposta por Bruno Latour (1997). Tsallis (2005) comenta que "recalcitrância acontece no terreno do vínculo, da relação. Ela explicita ... um acontecimento singular [e pode ser utilizada como] uma medida para estabelecer os possíveis mapas sobre a movimentação dos vínculos" (Tsallis, 2005, p. 20-23).

10. Criado e interpretado pelo mexicano Roberto Gómez Bolamos, o programa Chaves e Chapolin é exibido no canal de TV SBT.

\section{Referências}

Amarilian, M. L. T. (1997). Compreendendo o cego: Uma visão psicanalítica da cegueira por meio de desenhos-estórias. São Paulo, SP: FAPESP.

Batista, C. G. (2005). Formação de conceitos em crianças cegas: Questões teóricas e implicações educacionais. Psicologia: Teoria e Pesquisa, 21(1), 7-15.

Deleuze, G., \& Guattari, F. (1996). Como criar para si um corpo sem órgãos. In G. Deleuze \& F. Guattari (Eds.), Mil Platôs: Vol. 3. Capitalismo e esquizofrenia. Rio de Janeiro, RJ: Ed. 34.
Despret, V. (1999). Ces émotions que nous fabriquent. Paris: Les Empêcheurs de Penser en Rond-Seuil.

Despret, V. (2004a). Hans, Le cheval qui savait compter. Paris: Les Empêcheurs de Penser en Rond-Seuil.

Despret, V. (2004b). The body we care for: Figures of anthropozoo-genesis. Body and Society, 10(2-3), 111-134.

Latour, B. (1994). Jamais fomos modernos. Rio de Janeiro, RJ: Ed. 34.

Latour, B. (1997). Des sujets recalcitrants. La Recherce, 301, 8890.

Latour, B. (1999). How to talk about the body? The normative dimension of science studies. Body and Society, 10(2-3), 20529. Retirado em 2004, de http://www.ensmp.fr/ latour/articles/ article/077.html

Latour, B. (2000). A ciência em ação. Como seguir cientistas e engenheiros sociedade afora. São Paulo, SP: Editora da Universidade Estadual Paulista.

Latour, B. (2002). The promises of construtivism. In D. Idhe \& E. Selinger (Eds.), Chasing technoscience: Matrix of materiality (pp. 27-43). Indianápolis, IN: Indiana University Press. Retirado em 2004, de http://www.bruno-latour.fr/articles/article/ 087.html

Latour, B. (2003). Un monde pluriel mais commun. Entretiens avec François Ewald. Paris: Éditions de l'aube.

Masini, E. (1994). O perceber e o relacionar-se do deficiente visual. Brasília, DF: Coordenadoria Nacional para a Integração da Pessoa Portadora de Deficiência.

Rocha, M., \& Aguiar, K. (2003). Pesquisa intervenção e a produção de novas análises. Psicologia: Ciência e Profissão, 23(4), 64-73.

Santin, S., \& Simmons, J. (1996). Problemas das crianças portadoras de deficiência visual congênita na construção da realidade (I. Viegas, Trad.). Revista Benjamin Constant, 2, 4-11 (Reproduzido de Problems in the construction of reality in congenitally blind children. Journal of Visual Impairment and Blindness, 425, 1977). Retirado em 2004, de http:// www.deficientesvisuais.org.br/Artigo4.htm

Spink, P. (2003). Pesquisa de campo em Psicologia Social: Uma perspectiva pós-construcionista. Psicologia e Sociedade, 15(2), $18-42$.

Stengers, I. (2002). A invenção das ciências modernas. São Paulo: Ed. 34.

Stengers.I. (1990). Quem tem medo da ciência. Ciências e poderes. São Paulo, SP: Sicililano.

Tsallis, A. (2005). Entre terapeutas e palhaços: A recalcitrância em ação. Tese de Doutorado não-publicada, Universidade do Estado do Rio de Janeiro, RJ.

Marcia Moraes é Doutora em Psicologia Clínica pela Pontifícia Universidade Católica de São Paulo,

Professora do Programa de Pós-graduação strito sensu em Psicologia da Universidade Federal Fluminense e

Consultora Científica no Centro de Estudos sobre

Subjetividade, Cegueira e Baixa Visão do Instituto Benjamin Constant. Endereço para correspondência: Rua Desembargador Cesínio Paiva, 15, São Francisco, Niterói, RJ, 24360-530. Tel.: (21) 26100827 ou (21) 9631 9409. mmoraes@vm.uff.br 
A Contribuição da Antropologia Simétrica à Pesquisa e

Intervenção em Psicologia Social: Uma Oficina de

Expressão Corporal com Jovens Deficientes Visuais

Marcia Moraes

Recebido: 31/03/2007

$1^{a}$ revisão: $15 / 10 / 2007$

Aceite final: 04/12/2007 